\title{
Sistem Pendukung Keputusan Pemilihan Calon Ketua OSIS Menggunakan Metode Saw Pada Sma Negeri 3 Sigi Berbasis Website
}

\author{
Anisa Yulandari ${ }^{1)}$, Sukardi ${ }^{2)}$, Suryani Risqika ${ }^{3)}$ \\ 1) Tehnik Informatika, STMIK Adhi Guna Palu \\ 2), 3) Sistem Informasi, STMIK Adhi Guna Palu \\ Jl. Undata No. 3, Besusu Barat, Palu Timur, Palu 94111 \\ Emai : Anisayulandari@stmikadhiguna.ac.id ${ }^{1)}$, sukarvi@gmail.com $^{2)}{ }^{\text {suryanirisqika1312@gmail.com }}{ }^{3}$
}

\begin{abstract}
Abstrak
Sistem Pendukung Keputusan pemilihan calon ketua osis merupakan aplikasi yang didalamnya terdapat proses memilih siswa yang dapat menjadi calon ketua osis. Tujuan dari penelitian ini adalah merancang suatu sistem pendukung keputusan yang dapat menilai calon ketua osis yang ada di SMK Negeri 3 SIGI. Sistem ini dapat meminimalisir self-error maupun subjekvitas person dalam memilih calon ketua osis. Dalam penelitian ini menggunakan beberapa metode penelitian seperti teknik pengumpulan data yang digunakan adalah metode observasi, dokumentasi serta wawancara dan metode pengujian yang digunakan menggunakan metode blackbox. Adapun kesimpulan dalam penelitian ini adalah hasil rancangan dan pembuatan sistem yang ada dari segi fungsi tombol-tombol yang ada di website penilaian menghasilkan pengujian 100\%. Elemen-elemen dari system yakni tombol-tombol login, simpan, edit dan hapus berfungsi dengan baik sehingga dapat menjadi dasar dalam mengimplementasikan sistem pendukung keputusan tersebut.
\end{abstract}

Kata Kunci-Sistem Informasi, Ketua Osis, Metode SAW.

\begin{abstract}
Decision Support System for the election of student council president candidates is an application in which there is a process of selecting students who can become candidates for student council president. The purpose of this study is to design a decision support system that can assess candidates for student council leaders in SMK Negeri 3 SIGI. This system can minimize self-error and person subjectivity in selecting candidates for student council chairman. In this study using several research methods such as data collection techniques used are the method of observation, documentation and interviews and the testing method used is the blackbox method. The conclusions in this study are the results of the design and manufacture of existing systems in terms of the functions of the buttons on the assessment website resulting in $100 \%$ testing. The elements of the system, namely the login, save, edit and delete buttons function properly so that they can become the basis for implementing the decision support system.
\end{abstract}

Keywords-Decision Support System, Election of Student council president candidates, SAW

\section{PENDAHULUAN}

Organisasi Siswa Intra Sekolah (OSIS) merupakan suatu organisasi yang berada di tingkat sekolah di Indonesia yang dimulai dari Sekolah Menengah Pertama (SMP) dan Sekolah Menengah Atas (SMA). OSIS diurus dan dikelola oleh siswa-siswa yang terpilih untuk menjadi 
pengurus OSIS. Biasanya organisasi ini memiliki seorang pembimbing dari guru yang dipilih oleh pihak sekolah. Anggota OSIS adalah seluruh siswa yang berada pada satu sekolah tempat OSIS itu berada.

Ketua OSIS merupakan pimpinan tertinggi yang ada dalam suatu struktur organisasi kepengurusan OSIS. Seorang ketua OSIS akan sangat berpengaruh pada perkembangan kegiatan kesiswaan dalam suatu sekolah. Oleh karena itu ketua OSIS merupakan jabatan strategis untuk mencapai tujuan OSIS sebagai wadah bagi seluruh siswa dalam melaksanaakan berbagai kegiatan yang dapat mengaplikasikan potensi-potensi yang dimiliki oleh seluruh siswa.

Dalam proses penyeleksian yang ada, untuk mendapatkan calon ketua OSIS yang berkompeten bukan menjadi hal yang mudah, diperlukan proses seleksi yang baik dalam pemilihan seorang ketua OSIS yang mampu membawa keberhasilan kegiatan kesiswaan. Seleksi merupakan tahapan untuk memutuskan peserta pantas atau tidak menjabat di lembaga organisasi tersebut. Keputusan yang ada harus objektif agar kualitas yang diperoleh sesuai dengan harapan sehingga tidak ada pihak yang dirugikan. Keputusan ini biasanya didasarkan pada dasar-dasar penilaian tertentu sehingga dapat menjadi keputusan yang valid.

Setelah melakukan observasi di tempat peneltian, proses seleksi calon ketua OSIS yang ada didasarkan pada proses pendaftaran oleh siswa yang berniat menjadi pengurus OSIS. Hal ini menjadi kurang berhasil karena proses penjaringan yang ada, tidak mendapatkan siswa yang benar-benar berkompeten untuk menjadi ketua OSIS.

Untuk mencapai hal tersebut, diperlukan Sistem Pendukung Keputusan atau Decision Support System (DSS). DSS menyediakan fasilitas untuk melakukan analisis sehingga proses pengambilan keputusan yang dilakukan lebih berkualitas. [1].

Dalam penerapannya untuk mendukung seleksi calon ketua osis yanga ada diperlukan suatu metode dengan algoritma khusus yang dapat menseleksi calon ketua osis yang memenuhi kriteria yang ada seperti metode SAW (Simple Additive Weighting).

Dengan adanya sistem ini, dapat membantu pihak sekolah dalam proses seleksi calon ketua OSIS sehingga Ketua OSIS yang terpilih memiliki kompetensi yang baik sehingga kegiatan-kegiatan yang ada di sekolah tersebut dapat berjalan dengan sebagai mana mestinya.

\section{METODE PENELITIAN}

Dalam menyusun penelitian ini, Terdapat beberapa metode penelitian yang digunakan seperti: kerangka berfikir penelitian, sumber dasar teori, metode pengumpulan data, metode pengembangan sistem serta metode pengujian sistem yang berguna sebagai ke-valid-an dalam pembuatan aplikasi dalam penelitian ini. Berikut ini metode penelitian yang menyusun penelitian ini:

\subsection{Kerangka Berfikir}

Proses tahapan kerangka berfikir berfungsi sebagai alat bantu petunjuk yang menunjukkan kerangka umum penelitian ini yang dimulai dari problem, approach, implementation, software development, measurement \& result. Tahapan kerangka berfikir yang ada ditunjukkan jelas pada Gambar 1 .

\subsection{Dasar Teori}

Dasar teori yang digunakan dalam penelitian ini terlebih khusus menggunakan teori yang berhubungan dengan sistem pendukung keputusan dan algoritma metode $S A W$ itu sendiri. Berikut ini teori-teori yang digunakan dalam penelitian ini: 


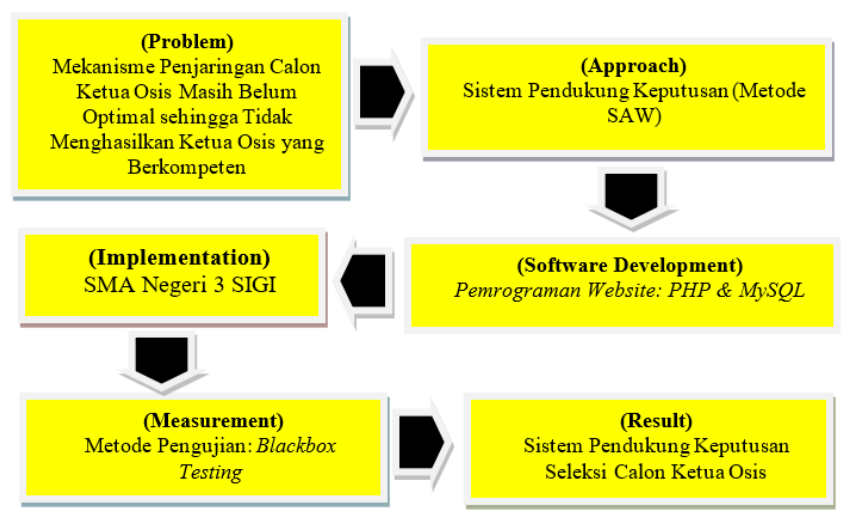

Gambar 1. Kerangka Berfikir

\subsubsection{Sistem Pendukung Keputusan (Decision Support System)}

Sistem Pendukung Keputusan (SPK) atau dikenal dengan nama decision support system (DSS) merupakan suatu sistem atau aplikasi yang terkomputerisasi untuk membantu para pimpinan berdasarkan data dan model yang ada yang berfungsi untuk memecahkan berbagai persoalan yang tidak terstruktur [2].

\subsubsection{Dasar Teori Simple Additive Weighting (SAW)}

Metode Simple Additive Weight (SAW), biasa juga disebut dengan istilah metode penjumlahan terbobot dimana Konsep dasar metode ini lebih menekankan pencarian penjumlahan terbobot dari rating penilaian pada setiap alternatif pada semua atribut [3]. Metode SAW merupakan metode yang paling ideal untuk membuat perankingan dari hasil seleksi dari beberapa alternative yang ada.

\subsection{Metode Pengumpulan Data}

Metode pengumpulan data yang digunakan dalam penelitian ini menggunakan metode observasi, wawancara, dokumentasi serta penyebaran angket kepada alternative dalam mengumpulkan penilaian kualitatif kriteria dari beberapa alternative yang dijadikan sampel.

\subsection{Metode Pengembangan Sistem}

Metode pengembangan sistem yang digunakan dalam penelitian ini yakni metode pengembagan sistem waterfall. Model Waterfall (model air terjun) merupakan model pengembangan sistem yang dibangun secara sekuensial. Adapun dalam proses pembuatannya mengikuti alur tahapan dari mulai proses analisis, proses desain, proses kode, proses pengujian serta pemeliharaan [4]

\subsection{Metode Pengujian Sistem}

Metode pengujian sistem yang digunakan dalam penelitian ini yakni metode pengujian blackbox testing. Metode Black-Box Testing merupakan suatu metode pengujian yang berfokus pada persyaratan fungsional perangkat lunak yang ada seperti fungsionalitas tombol yang ada di perangkat lunak dan lain sebagainya [5]

\section{HASIL DAN PEMBAHASAN}

Berdasarkan metode penelitian di atas, maka hasil dan pembahasan dalam penelitian ini dibuat berdasarkan hasil tampilan pembuatan sistem setelah dijalankan serta perhitungan yang ada dalam metode SAW itu sendiri.

\subsection{Hasil Permodelan Sistem}

Adapun hasil permodelan system dalam penelitian ini ditunjukkan pada Gambar 2. Dalam tahapan ini, peneliti membuat pemodelan algorintma SAW yang dituangkan dalam pengkodean aplikasi yang ada. 


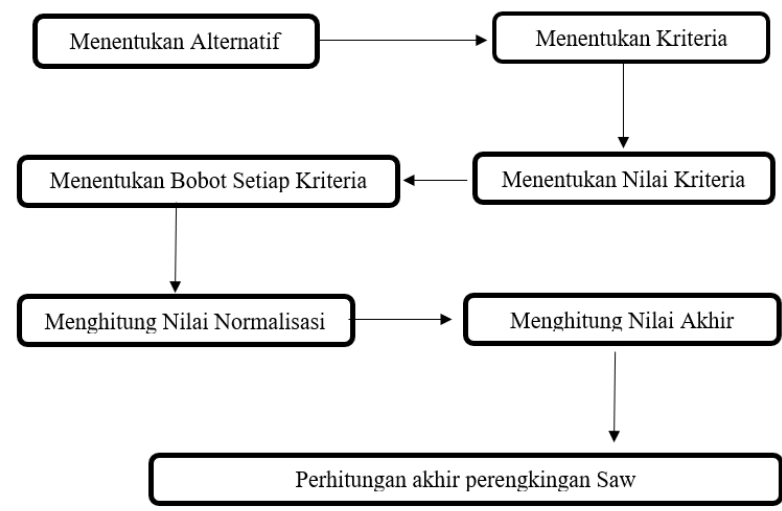

Gambar 2. Permodelan Algoritma SAW

\subsection{Hasil Perancangan Sistem}

Hasil perancangan sistem yang ada dalam penelitian ini dilakukan berdasarkan konteks diagram yang ditunjukkan pada Gambar 3. SPK Calon Ketua Osis memiliki dua objek utama yakni admin dan siswa. Selain itu dalam perancangan sistem untuk membantu peneliti dalam menyusun database spk calon ketua osis dituangkan pada diagram alir data yang ditunjukkan pada Gambar 4.

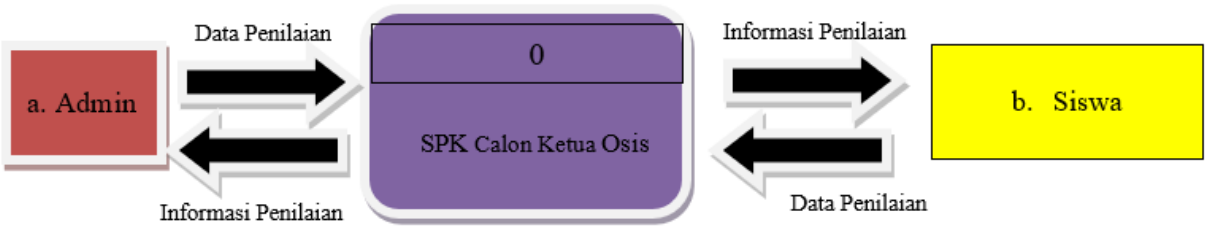

Gambar 3. Konteks Diagram

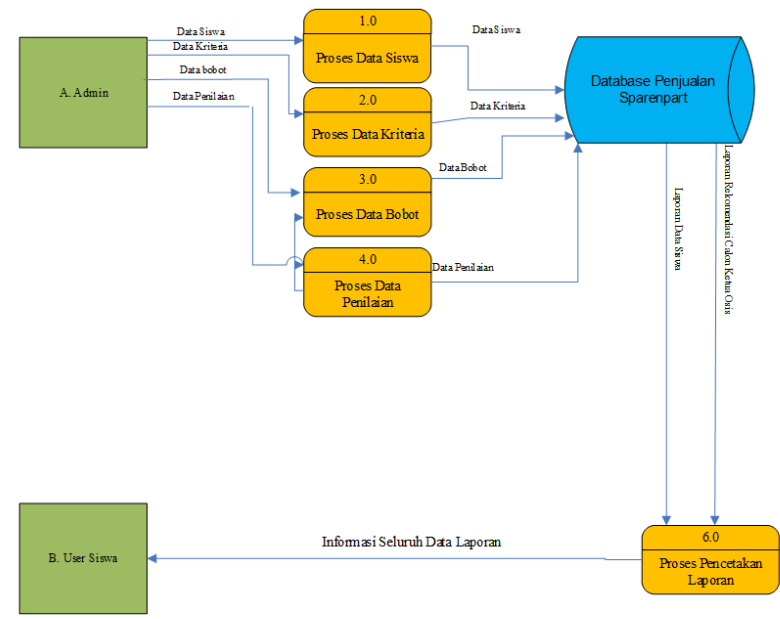

Gambar 4. Konteks Diagram

\subsection{Hasil Implementasi Sistem}

Hasil implementasi sistem terdiri dari beberapa tampilan printscreen program yang telah dibangun dengan menggunakan Bahasa pemrograman website dengan menggunakan Bahasa PHP dan MySql. Adapun tampilan secara umum adalah sebagai berikut 


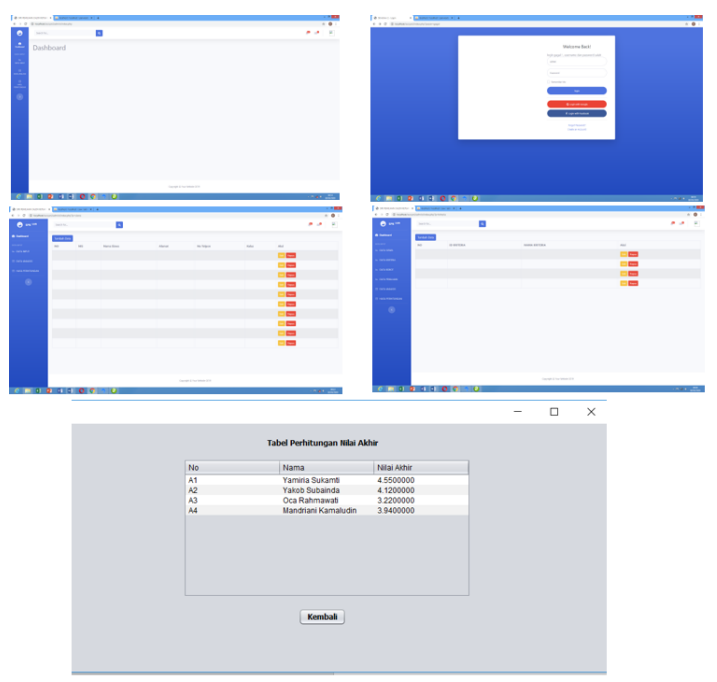

Gambar 5. Hasil Implementasi SPK

\subsection{Hasil Pengujian}

3.2.1 Pengujian Metode Simple Additive Weighting

Pengujian metode SAW didasarkan dari penjabaran dari langkah-langkah dari algoritma SAW itu sendiri. Langkah-langkah metode SAW adalah sebagai berikut:

A. Menentukan alternatif (Simbol A)

Alternatif adalah objek data latih yang akan dinilai berdasarkan topik penelitian yang diangkat. Alternatif yang digunakan dalam penelitian ini sesuai dengan tabel alternatif pada tabel 4.1. Berikut ini akan dijelaskan secara detail: A1 sebagai Yamiria;sebagai Yakob; A3 sebagai Oca; A4 sebagai Man

B. $\quad$ Menentukan kriteria (Simbol C)

Kriteria adalah faktor yang dapat mempengaruhi nilai hasil perhitungan akhir dari metode SAW ini. Adapun kriteria yang digunakan secara detail akan dijelaskan sebagai berikut:

C1: Kehadiran Siswa

- Kehadiran $>=20$ hari $=5$

- Kehadiran $>=15<20$ hari $=4$

- Kehadiran $>=10<15$ hari $=3$

- Kehadiran $>=5<10$ hari $=2$

- Kehadiran $>=0<5$ hari $=1$

C2: Tepat Waktu

- Tepat Waktu >= 20 hari $=5$

- Tepat Waktu >= $15<20$ hari $=4$

- Tepat Waktu >=10<15 hari $=3$

- Tepat Waktu >= $5<10$ hari $=2$

- Tepat Waktu >=0 $<5$ hari $=1$

C3: Sanksi Siswa

- Sanksi 0 Kali $=5$

- Sanksi $>0<=5=4$

- Sanksi $>5<=10=3$

- Sanksi $>10<=15=2$

- Sanksi $>15=1$

C4: Kesalahan Penyelesaian Pekerjaan

- KPP O Kali $=5$

$-K P P>0<=5=4$

$-K P P>5<=10=3$ 
$-K P P>10<=15=2$

$-K P P>15=1$

C5: Penyelesaian Pekerjaan Sesuai SOP

- PPSS > $10 \mathrm{Kali}=5$

- PPSS $>8<=10=4$

- PPSS $>5<=8=3$

- PPSS $>3<=5=2$

- PPSS $<3=1$

C6: Kemampuan Menyelesaikan Masalah

- Sangat Baik = 5

- Baik = 4

- Cukup = 3

- Buruk = 2

- Sangat Buruk = 1

C7: Kemampuan Beradaptasi Dengan Kelompok Kerja

- Sangat Baik = 5

- Baik = 4

- Cukup = 3

- Buruk = 2

- Sangat Buruk = 1

C8: Kemampuan Memimpin Dalam Team

- Sangat Baik = 5

- Baik = 4

- Cukup $=3$

- Buruk = 2

- Sangat Buruk = 1

C Menentukan bobot (Simbol B)

Bobot adalah tingkat kepentingan dari suatu kriteria dimana bobot ini yang menentukan calon seperti apa yang akan terpilih dari proses perhitungan kriteria yang ada.

D Menentukan nilai kriteria

Nilai kriteria adalah nilai yang diperoleh masing-masing alternatif berdasarkan atributatribut sesuai dengan kriteria-kriteria yang telah ditetapkan. Adapun nilai kriteria setiap alternative adalah sebagai berikut:

Tabel 1

Data Sampel Alternatif

\begin{tabular}{|c|c|c|c|c|}
\hline No & Alternatif & C1 & C2 & C3 \\
\hline 1 & Yamiria (A1) & $4(\mathrm{C} 11)$ & $5(\mathrm{C} 25)$ & $5(\mathrm{C} 35)$ \\
\hline 2 & Man (A2) & $4(\mathrm{C} 12)$ & $3(\mathrm{C} 23)$ & $3(\mathrm{C} 33)$ \\
\hline 3 & Yakob (A3) & $3(\mathrm{C} 13)$ & $4(\mathrm{C} 24)$ & $4(\mathrm{C} 34)$ \\
\hline 4 & Oca (A4) & $1(\mathrm{C} 15)$ & $5(\mathrm{C} 25)$ & $1(\mathrm{C} 31)$ \\
\hline
\end{tabular}

E $\quad$ Menghitung normalisasi

Rumus untuk melakukan normalisasi bobot yakni: bobot nilai kriteria yang terpilih / tertinggi dari bobot tersebut.

Contoh untuk A1

$\mathrm{C} 1$ : C11 (5) / nilai tertinggi dari kriteria c1

$$
=5 / 5
$$

$=1$

C2: C21 (5) / nilai tertinggi dari kriteria c2

$$
\begin{aligned}
& =5 / 5 \\
& =1
\end{aligned}
$$


C3: C31 (5) / nilai tertinggi dari kriteria c3

$=5 / 5$

$=1$

C4: C41 (5) / nilai tertinggi dari kriteria c4

$=5 / 5$

$=1$

C5: C51 (5) / nilai tertinggi dari kriteria c5

$=5 / 5$

$=1$

C6: C61 (5) / nilai tertinggi dari kriteria c6

$=5 / 5$

$=1$

C7: C71 (5) / nilai tertinggi dari kriteria c7

$=5 / 5$

$=1$

C8: C81 (5) / nilai tertinggi dari kriteria c8

$=5 / 5$

$=1$

F $\quad$ Menghitung nilai akhir

Nilai akhir adalah perhitungann nilai normalisasi dikalikan dengan nilai bobot dari setiap nilai kriteria Berikut ini adalah proses perhitungan nilai akhir masing-masing alternatif:

Tabel 2

Rangking Nilai Kriteria

\begin{tabular}{|c|l|c|c|}
\hline No & Nama & Nilai Ai & Hasil \\
\hline 1 & Yamiria & 4.550 & Layak \\
\hline 2 & Yakob & 4.120 & Layak \\
\hline 3 & Mandriani & 3.94 & Layak \\
\hline 4 & Oca & 3.220 & Layak \\
\hline
\end{tabular}

3.2.2 Hasil Pengujian Menggunakan Blackbox Testing

Setelah melakukan pengujian menggunakan blackbox testing diperoleh hasil yang ditunjukkan pada Gambar 6-8 sebagai berikut :

\begin{tabular}{|c|c|c|c|c|c|c|c|c|}
\hline No & \begin{tabular}{|c|} 
ITEM \\
PENGUUAAN
\end{tabular} & $\begin{array}{l}\text { JUMLAH } \\
\text { TOMBOL/AKS } \\
\text { I }\end{array}$ & $\begin{array}{c}\begin{array}{c}\text { JUMLAH } \\
\text { RENCANA }\end{array} \\
\text { UII }\end{array}$ & $\begin{array}{l}\text { TOTAL } \\
\text { UI }\end{array}$ & FORM & PENGUIIAN & KESIMPULAN & POIN \\
\hline \multirow{18}{*}{1} & \multirow{18}{*}{$\begin{array}{l}\text { Fasilitas } \\
\text { Tombol } \\
\text { Simpan }\end{array}$} & \multirow{3}{*}{1 Tombol } & \multirow{3}{*}{$\begin{array}{l}3 \text { Kali } \\
\text { Operasi } \\
\text { simpan }\end{array}$} & \multirow{3}{*}{3 Kali } & \multirow{3}{*}{ Input Data Siswa } & Pengujian Input 1 & Berhasil & 1 \\
\hline & & & & & & Pengujian Input 2 & Berhasil & 1 \\
\hline & & & & & & Pengujian Input 3 & Berhasil & 1 \\
\hline & & \multirow{3}{*}{1 Tombol } & 3 Kali & \multirow{3}{*}{3 Kali } & \multirow{3}{*}{$\begin{array}{c}\text { Input Data } \\
\text { Kriteria }\end{array}$} & Pengujian Input 1 & Berhasil & 1 \\
\hline & & & Operasi & & & Pengujian Input 2 & Berhasil & 1 \\
\hline & & & Simpan & & & Pengujian Input 3 & Berhasil & 1 \\
\hline & & \multirow{3}{*}{1 Tombol } & 3 Kali & \multirow{3}{*}{3 Kali } & \multirow{3}{*}{ Input Data Bobot } & Pengujian Input 1 & Berhasil & 1 \\
\hline & & & Operasi & & & Pengujian Input 2 & Berhasil & 1 \\
\hline & & & Simpan & & & Pengujian Input 3 & Berhasil & 1 \\
\hline & & \multirow{3}{*}{1 Tombol } & & \multirow{3}{*}{3 Kali } & \multirow{3}{*}{$\begin{array}{l}\text { Input Data } \\
\text { Penilaian }\end{array}$} & Pengujian Input 1 & Berhasil & 1 \\
\hline & & & Operasi & & & Pengujian Input 2 & Berhasil & \\
\hline & & & & & & Pengujian Input 3 & Berhasil & 1 \\
\hline & & \multirow{3}{*}{1 Tombol } & 3 Kali & \multirow{3}{*}{3 Kali } & \multirow{3}{*}{$\begin{array}{c}\text { Input Data } \\
\text { detail_kriteria }\end{array}$} & Pengujian Input 1 & Berhasil & 1 \\
\hline & & & Operasi & & & Pengujian Input 2 & Berhasil & 1 \\
\hline & & & & & & Pengujian Input 3 & Berhasil & 1 \\
\hline & & \multirow{3}{*}{1 Tombol } & & \multirow{3}{*}{3 Kali } & \multirow{3}{*}{ Input Data Rating } & Pengujian Input 1 & Berhasil & 1 \\
\hline & & & Operasi & & & Pengujian Input 2 & Berhasil & 1 \\
\hline & & & Simpan & & & Pengujian Input 3 & Berhasil & 1 \\
\hline & & \multicolumn{2}{|l|}{ Jumlah } & \multicolumn{3}{|c|}{18 Total L } & \multicolumn{2}{|l|}{$18 \mathrm{Tot}$} \\
\hline
\end{tabular}

Gambar 6. Hasil Pengujian Blackbox Testing Bagian Input 


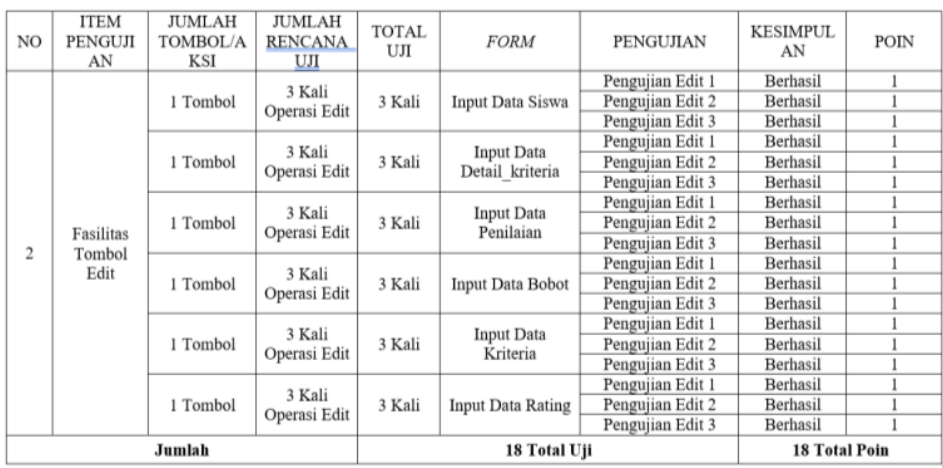

Gambar 7. Hasil Pengujian Blackbox Testing Bagian Edit

\begin{tabular}{|c|c|c|c|c|c|c|c|c|}
\hline No & $\begin{array}{c}\text { ITEM } \\
\text { PENGUJIAN }\end{array}$ & $\begin{array}{c}\text { JUMLAH } \\
\text { TOMBOL/AKSI }\end{array}$ & $\begin{array}{l}\text { JUMLAH } \\
\text { RENCANA } \\
\text { UJI }\end{array}$ & $\begin{array}{c}\text { TOTAL } \\
\text { UII }\end{array}$ & FORM & PENGUIIAN & KESIMPULAN & POIN \\
\hline \multirow{17}{*}{3} & \multirow{17}{*}{$\begin{array}{c}\text { Fasilitas } \\
\text { Tombol Hapus }\end{array}$} & \multirow[b]{2}{*}{1 Tombol } & 3 Kali & \multirow[b]{2}{*}{3 Kali } & \multirow{2}{*}{$\begin{array}{c}\text { Input Data } \\
\text { Siswa }\end{array}$} & Pengujian Hapus 1 & Berhasil & 1 \\
\hline & & & $\begin{array}{l}\text { Operasi } \\
\text { Hanus }\end{array}$ & & & $\begin{array}{l}\text { Pengujian Hapus } 2 \\
\text { Penvivian }\end{array}$ & Berhasil & 1 \\
\hline & & \multirow{3}{*}{1 Tombol } & & \multirow{3}{*}{3 Kali } & \multirow{3}{*}{$\begin{array}{c}\text { Input Data } \\
\text { Detail_kriteri } \\
\bar{a}\end{array}$} & $\begin{array}{l}\text { Pengujian Hapus } 3 \\
\text { Pengujian Hapus } 1\end{array}$ & $\begin{array}{l}\text { Berrassin } \\
\text { Berhasil }\end{array}$ & $\frac{1}{1}$ \\
\hline & & & Operasi & & & Pengujian Hapus 2 & Berhasil & 1 \\
\hline & & & Hapus & & & Pengujian Hapus 3 & Berhasil & 1 \\
\hline & & \multirow{3}{*}{1 Tombol } & & \multirow{3}{*}{3 Kali } & \multirow{3}{*}{$\begin{array}{c}\text { Input Data } \\
\text { Penilaian }\end{array}$} & Pengujian Hapus 1 & Berhasil & 1 \\
\hline & & & Operasi & & & Pengujian Hapus 2 & Berhasil & $\frac{1}{1}$ \\
\hline & & & & & & Pengujian Hapus 3 & Berhasil & 1 \\
\hline & & \multirow{3}{*}{1 Tombol } & 3 Kali & \multirow{3}{*}{3 Kali } & \multirow{3}{*}{$\begin{array}{c}\text { Input Data } \\
\text { Laporan }\end{array}$} & Pengujian Hapus 1 & Berhasil & 1 \\
\hline & & & Operasi & & & Pengujian Hapus 2 & Berhasil & 1 \\
\hline & & & & & & Pengujian Hapus 3 & Berhasil & \\
\hline & & \multirow{3}{*}{1 Tombol } & 3 Kali & \multirow{3}{*}{3 Kali } & \multirow{3}{*}{$\begin{array}{c}\text { Input Data } \\
\text { Bobot }\end{array}$} & Pengujian Hapus 1 & Berhasil & 1 \\
\hline & & & Operasi & & & Pengujian Hapus 2 & Berhasil & 1 \\
\hline & & & Hapus & & & Pengujian Hapus 3 & Berhasil & 1 \\
\hline & & \multirow{3}{*}{1 Tombol } & 3 Kali & \multirow{3}{*}{3 Kali } & \multirow{3}{*}{$\begin{array}{c}\text { Input Data } \\
\text { Rating }\end{array}$} & Pengujian Hapus 1 & Berhasil & 1 \\
\hline & & & Operasi & & & Pengujian Hapus 2 & Berhasil & 1 \\
\hline & & & Hapus & & & Pengujian Hapus 3 & Berhasil & 1 \\
\hline \multicolumn{4}{|c|}{ Jumlah } & \multicolumn{3}{|c|}{18 Total Uji } & \multicolumn{2}{|c|}{18 Total Poin } \\
\hline
\end{tabular}

Gambar 8. Hasil Pengujian Blackbox Testing Bagian Hapus

Adapun untuk mengetahui hasil akhir dari pengujian blackbox testing yang ada maka ditentukan dengan rumus sebagai berikut:

$$
\text { Hasil_blackboxtest }=\frac{\text { jumlah point }}{\text { jumlah uji }} \times 100 \%
$$

Hasil Pengujian blackboxtext $=(18+18+18) / 54$ X 100\% $=100 \%$. Dari Hasil pengujian yang dilakukan dengan metode black box testing, semua komponen tombol simpan, tombol edit dan tombol delete, dapat berfungsi dengan baik. Berdasarkan hasil perhitungan di atas maka diperoleh hasil $100 \%$. Adapun untuk mengukur keberhasilan dari penelitian ini maka peneliti menggunakan parameter keberhasilan yang diuji dengan kelayakan penggunaannya berdasarkan tabel 3 berikut ini:

Tabel 3

Skala Penilaian Keberhasilan Penelitian

\begin{tabular}{|c|c|c|}
\hline No. & Skala & Keterangan \\
\hline 1 & $90 \%$ sampai $100 \%$ & Sangat Layak \\
\hline 2 & $80 \%$ sampai $89,99 \%$ & Layak \\
\hline 3 & $70 \%$ sampai $79,99 \%$ & Cukup Layak \\
\hline 4 & $60 \%$ sampai $69,99 \%$ & Kurang Layak \\
\hline 5 & $0 \%$ sampai $59,99 \%$ & Tidak Layak \\
\hline
\end{tabular}

Berdasarkan hasil yang didapatkan sebelumnya dengan menggunakan blackbox testing maka penelitian ini dapat di kategorikan "Sangat Layak" untuk diterapkan di tempat penelitian yang ada. 


\section{KESIMPULAN}

Berdasarkan hasil di atas maka SPK seleksi calon ketua osis dengan menggunakan metode SAW menunjukan bahwa bahwa sistem ini dapat diterapkan di tempat penelitian dengan hasil uji blackbox testing mencapai $100 \%$ dan dikategorikan sangat layak berdasarkan tabel keberhasilan penelitian.Oleh karena itu sistem ini dapat diterapkan di tempat penelitian.

\section{SARAN}

Saran dari peneliti: Untuk peneliti selanjutnya agar supaya dapat ditambahkan kuesioner online agar supaya dapat mengambil data pada sistem itu sendiri sehingga tidak mengambil sumber eksternal dan juga kiranya dapat ditambahkan kriteria lainnya yang berhubungan sehingga perhitungan yang ada menjadi lebih detail lagi.

\section{UCAPAN TERIMA KASIH}

Peneliti mengucapkan banyak terima kasih kepada para pihak yang membantu dalam penyusunan penelitian itu juga. Selain itu, peneliti juga berterima kasih juga kepada Lembaga STMIK Adhi Guna serta pihak terkait seperti bagian LPPM yang memfasilitasi peneliti dalam penerbitan jurnal ini. Dan Terima kasih yang terakhir untuk pembaca artikel ini. Semoga penelitian ini dapat berguna untuk kita sekalian.

\section{DAFTAR PUSTAKA}

[1] Kusrini. 2007. Konsep dan Aplikasi Sistem Pendukung Keputusan.CV Andi Offset:Yogyakarta.

[2] Dewanto, J.I, dan Adhikara, A.MF., 2015, Sistem Penunjang Keputusan Investasi Saham dengan Metode SAW di Bursa Efek Jakarta, Skripsi, Teknik Informatika Universitas Esa Unggul, Jakarta.

[3] Munthe, Hotmaria Ginting. 2013. Sistem Pendukung Keputusan Penentuan Prioritas Usulan Sertifikasi Guru Dengan Metode Simple Additive Weighting. ISSN: 2301-9425. Medan: Pelita Informatika Budi Darma Vol IV, No. 2 Agustus 2013: 52-58

[4] Pressman, R.S. 2015. Rekayasa Perangkat Lunak: Pendekatan Praktisi Buku I. Yogyakarta: Andi.

[5] Pressman, Roger. 2005. Software Engineering: A Practitioner's Approach. New York : McGraw-Hill. 